\title{
Rehydration during exercise prevents the increase of homocysteine concentrations
}

\author{
Beatriz Maroto-Sánchez ${ }^{1}$. Olga Lopez-Torres ${ }^{1} \cdot$ Jara Valtueña $^{1} \cdot$ Pedro J. Benito ${ }^{2}$ Gonzalo Palacios ${ }^{1,3}$. \\ Ángel Enrique Díaz-Martínez ${ }^{4}$ Domingo González-Lamuño ${ }^{5}$. Angelo Zinellu6 Marcela González-Gross $^{1,3}$. \\ Ciriaco Carru ${ }^{6,7}$ (1)
}

\begin{abstract}
This study aimed to assess the effect of rehydration during and after acute aerobic submaximal exercise on total homocysteine (tHcy) concentrations and related parameters in physically active adult males. Twenty trained males $(29.4 \pm 7.9$ years old) completed four exercise tests: two without rehydration during exercise ( $\mathrm{NH} 1$ and $\mathrm{NH} 2$ ), one with rehydration during exercise using water (H1) and one with rehydration during exercise using an isotonic sports drink (H2). After finishing the exercise tests, subjects followed a rehydration protocol for $2 \mathrm{~h}$. Serum tHcy, vitamin B12, folate, creatine and creatinine were analysed before, after and at 2, 6 and $24 \mathrm{~h}$ after exercise. Data were analysed with and without correcting for haemoconcentration to assess the changes in tHcy related. The methylenetetrahydrofolate reductase (MTHFR) 677TT genotype was also analysed. THcy (uncorrected by haemoconcentration) increased significantly after exercise $(P<0.05)$ in the NH1 and NH2 tests [mean increase \pm SD: $1.55 \pm 0.33(15.18 \%)$ and $1.76 \pm 0.25(17.69 \%) \mu \mathrm{mol} / \mathrm{L}$, respectively], while no significant differences were found in the $\mathrm{H} 1$ and $\mathrm{H} 2$ tests [mean increase: $0.65(6.29 \%)$ and $0.90(8.69 \%) \mu \mathrm{mol} / \mathrm{L}$, respectively]. The increase was partly due to haemoconcentration and partly due to the metabolism underlying acute exercise. THcy concentrations recovered to baseline after $24 \mathrm{~h}$ in all tests. In conclusion, adequate rehydration during acute aerobic exercise using either water or a sports drink maintains tHcy concentrations at baseline and for up to $2 \mathrm{~h}$ after exercise in physically active male adults and prevents further increases when compared to no rehydration.
\end{abstract}

Keywords Homocysteine $\cdot$ Hydration $\cdot$ Vitamins $\cdot$ Metabolism

\section{Introduction}

Elevated total serum homocysteine (tHcy) is consistently considered as a powerful independent predictor of coronary heart disease, cerebrovascular disease and venous

Handling Editor: H. Jakubowski.

Beatriz Maroto-Sánchez

b.marotosanchez@gmail.com

$\triangle$ Ciriaco Carru

carru@uniss.it

1 ImFine Research Group, Department of Health and Human Performance. Faculty of Physical Activity and Sport Sciences (INEF), Universidad Politécnica de Madrid, Madrid, Spain

2 LFE Research Group, Department of Health and Human Performance. Faculty of Physical Activity and Sport Sciences (INEF), Universidad Politécnica de Madrid, Madrid, Spain thrombosis (Joubert and Manore 2006). Evidence also supports high tHcy concentrations as an independent risk factor for atherosclerotic disease in the coronary, cerebral and peripheral vessels (Boushey et al. 1995); however, the debate has recently opened into whether Hcy is a marker or a causative agent (Petras et al. 2014).

Institute of Health Carlos III, CIBERobn CB 12/03/30038, Madrid, Spain

4 AEPSAD. High Sports Council, Madrid, Spain

5 Pediatric Division, Hospital universitario Marqués de Valdecilla-Universidad de Cantabria and Research Institute Valdecilla (IDIVAL), Santander, Cantabria, Spain

6 Department of Biomedical Sciences, University of Sassari, Sassari, Italy

7 Quality Control Unit, Hospital University of Sassari (AOU), Sassari, Italy 
Controversial data have recently been published regarding the effect of physical exercise on tHcy concentrations; however, several studies have consistently demonstrated an increase in tHcy immediately after acute aerobic exercise (Deminice et al. 2014, 2016; Gelecek et al. 2007; Herrmann et al. 2003b; Iglesias-Gutierrez et al. 2012; Maroto-Sanchez et al. 2016).

The exact mechanism through which exercise affects tHcy concentrations remains poorly investigated. During prolonged exercise, skeletal muscle increases protein and amino acid catabolism (Brosnan et al. 2011), which is a cortisol-dependent regulation that results in the simultaneous uptake of amino acids into the liver to induce glucose synthesis (Powers and Howley 2007). Exercise increases the pool of amino acids in the muscle (Van Hall et al. 1999a), therefore, it could also increase the protein turnover and the catabolism of methionine and Hcy formation (Rennie and Tipton 2000; Joubert and Manore 2006). This could alter tHcy concentrations by increasing methionine metabolism or by decreasing B-vitamin availability (Joubert and Manore 2006). Studies have also shown increased plasma and muscle free amino acids after acute exercise (Van Hall et al. 1999b; Venta et al. 2009; Deminice et al. 2011), which can reduce glycogen reserves that, in turn, increase the demand for vitamin B-6 and folate (Herrmann et al. 2003a) that are required for Hcy catabolism and removal, respectively. On the other hand, an increase in methyl group turnover (which implicates creatine synthesis) during high-intensity exercise appears to be another important link between increased tHcy concentrations and exercise (Joubert and Manore 2006). Exercise clearly increases the demand for several methylated compounds, such as DNA, epinephrine, acetylcholine, carnitine and creatine (Venta et al. 2009; Deminice et al. 2011), which along with Hcy are products of transmethylation reactions. On the other hand, Sotgia et al. (2007) demonstrated that exercise-induced variations in Hcy concentrations were related to changes in the concentration of plasma creatine, which is an important methylated compound.

Hcy metabolism is affected by several enzyme mutations, the most prevalent of which is the methylenetetrahydrofolate reductase (MTHFR) C677T polymorphism. This polymorphism is associated with decreased enzyme activity, which eventually leads to elevated Hcy concentrations. The relationship between the reduced activity of the MTHFR enzyme and increased Hcy and cardiovascular disease (CVD) risk has been extensively investigated (Fukuda et al. 2014; González et al. 2016).

Prolonged exercise induces marked dehydration and hyperthermia if fluid losses are not replaced during exercise. The detrimental effects of dehydration on cardiovascular, thermoregulatory and metabolic functions are well documented (Sawka and Coyle 1999; Gonzalez-Alonso et al. 2008; Laitano et al. 2012). Recent research demonstrated that a small degree of hypohydration induced by moderate exercise and fluid restriction significantly impaired endothelial function (Arnaoutis et al. 2016), mechanism closely related to Hcy metabolism (Joubert and Manore 2006). Previous studies provided compelling evidence that dehydration when exercising in the heat resulted in significant perturbations in cardiovascular function in healthy humans compared with euhydrated normothermic and euhydrated heat-stressed individuals (Gonzalez-Alonso et al. 2008). A proper rehydration protocol during exercise influences cardiovascular function, thermoregulatory function, muscle performance, plasma and fluid volume status and exercise performance (Casa et al. 2000).

Rehydration is an important factor that restores all physiological systems in the human body and is implicated in restoring plasma volume. Rehydration should be taken into account as a possible factor not only for restoring water, glycogen and electrolyte losses or recovering plasma volume but also for being potentially implicated in affecting blood parameters by exercise and dehydration, as is the case with Hcy.

No data exist regarding the effect of rehydration during exercise on tHcy concentrations. Several studies have looked at both the acute and chronic Hcy response to exercise; however, none have directly investigated the interaction with rehydration. Therefore, the purpose of this study was to assess the effects of dehydration and rehydration on the Hcy response to acute aerobic exercise and its related parameters (i.e. folate, vitamin $\mathrm{B}_{12}$, creatine and creatinine).

\section{Material and methods}

The present study is a randomized and counterbalanced crossover design, were each participant acts as his own control.

\section{Participants}

Twenty males (mean age $29.4 \pm 7.9$ year) without known pathology, healthy and physically active (at least 3 days per week of aerobic exercise) were recruited at the Faculty of Physical Activity and Sport Sciences-INEF of the Technical University of Madrid (Spain).

The sample selection and study protocol were performed following the ethical guidelines of the Declaration of Helsinki for research involving human subjects (World Medical Association, 2004). Participants were informed of the nature and purpose of the study and signed an informed consent prior to conducting the tests. The protocol was approved by the Ethics Review Board of the Technical University of Madrid. 


\section{Inclusion and exclusion criteria}

Inclusion criteria were to be male, physically active (at least 3 days per week of aerobic exercise), non-smoker and healthy (not having any of the diseases listed below).

Exclusion criteria were to have any central or peripheral cardiovascular risk factor, diabetes, kidney or liver problems, known asthmatic complications, total cholesterol $>200 \mathrm{mg} /$ $\mathrm{dL}$, systolic blood pressure $>140 \mathrm{mmHg}$ or diastolic blood pressure $>90 \mathrm{mmHg}$, smoker, alcohol intake $>22 \mathrm{~g} /$ day history of inflammation or cancer, orthopaedic limitations, medications that may affect metabolic and cardiovascular function, vegetarian diets, intake of B-vitamins supplement or fortified food during the last 2 months.

\section{Medical examination}

On their first visit, subjects were required to complete a medical examination to ensure that there was no medical contraindication to them participating in the study. A basal electrocardiogram was performed with the Jaeger ${ }^{\circledR}$ electrocardiograph (Erich Jaeger, Germany). In addition, body mass $(\mathrm{kg})$ with a Detecto ${ }^{\circledR}$ scale (Lafayette Instruments Company, Lafayette, Indiana, USA), and height ( $\mathrm{cm})$ with a conventional rack stadiometer (Holtain Limited, Crymych, UK) were registered with the standard method by the Frankfurt Plane position. Body composition (Body mass, water content, Fat mass, Lean body mass, Body Mass Index, and Basal Metabolism) was analysed by Bioelectrical Impedance Analysis (BIA) with a TANITA BC 418 MA (Tanita Corp., Tokyo, Japan).

During this session, subjects completed an incremental maximal test on a treadmill (H/P/COSMOS ${ }^{\circledR} 3 \mathrm{P} 4.0, \mathrm{H} / \mathrm{P} /$
Cosmos Sports \& Medical, Nussdorf-Traunstein, Germany), according to the protocol described by Myers and Bellin (2000). Individual maximal oxygen uptake $\left(\mathrm{VO}_{2 \max }\right)$ of each subject was determined to establish the individual load at $65 \%$ of oxygen consumption $\left(\mathrm{VO}_{2}\right)$ for each subject for the further tests of the study.

\section{Randomization}

Participants were randomly assigned through counterbalanced drawing to complete the 2 non-rehydration tests: NH1 and $\mathrm{NH} 2$; and then, the 2 rehydration tests, $\mathrm{H} 1$ and $\mathrm{H} 2$.

The type of liquid after each test was randomized and counterbalanced.

\section{Exercise protocol}

All participants completed four exercise tests of $40 \mathrm{~min}$ at constant load with an intensity of $65 \%$ of their individual $\mathrm{VO}_{2 \max }$ on a treadmill as described previously (MarotoSanchez et al. 2013). Tests were performed in a hot environment to get the subjects dehydrated (mean temperature of $30{ }^{\circ} \mathrm{C}$ and $60 \%$ of mean relative humidity), controlled by heaters and a weather station. Two of the exercise tests were performed without rehydration during exercise (NH1 and $\mathrm{NH} 2$ ) and the other two tests with rehydration during exercise (H1 and H2) (Fig. 1). After finishing all of the tests participants followed a rehydration protocol (See below rehydration protocol).

During exercise tests, heart rate (HR) was controlled using a Polar $\mathrm{S} 810^{\circledR}$ (Polar Electro, Kempele, Finland); the $\mathrm{VO}_{2}$ and ventilation (VE) were measured with the gas analyzer Jaeger Oxycon Pro (Erich Jaeger, Viasys Healthcare,

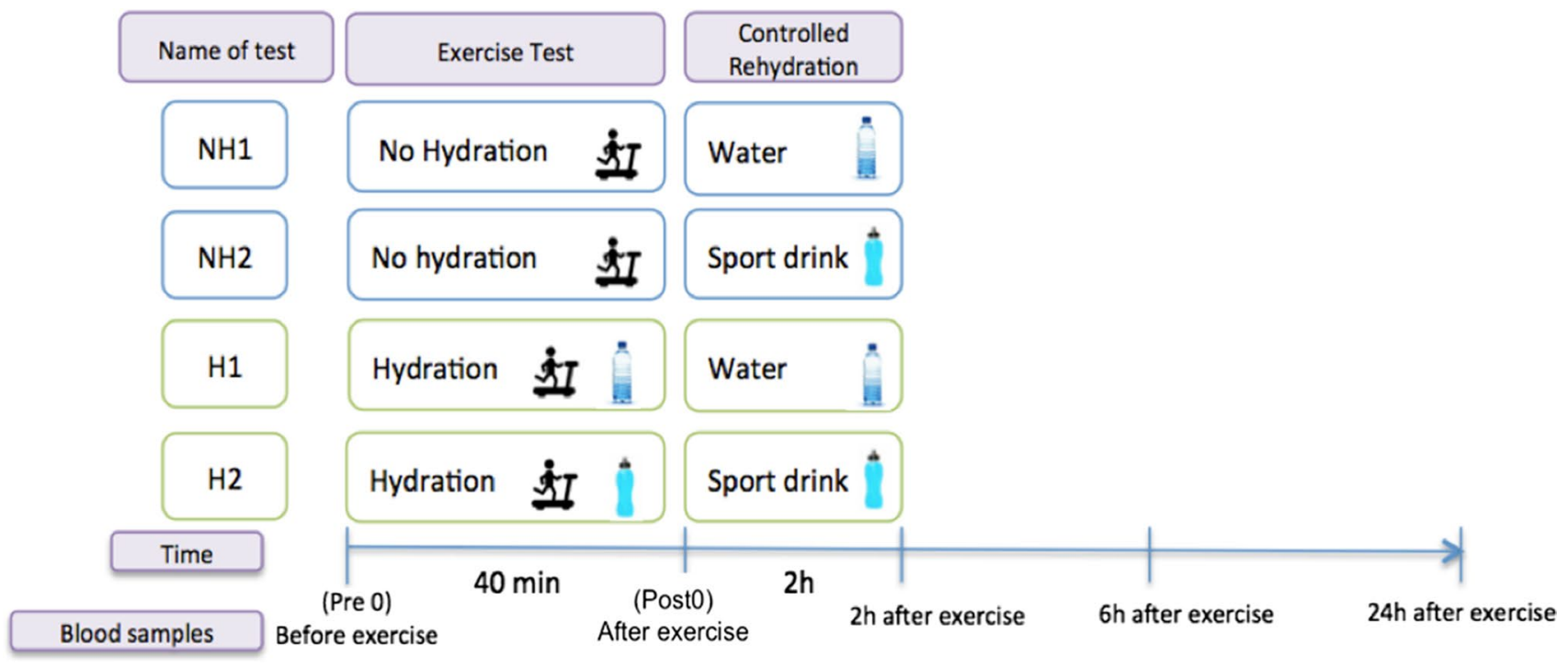

Fig. 1 Experimental protocol 
Germany). Blood pressure (BP) was measured before and after each exercise test.

\section{Rehydration protocol}

Participants were weighed under the same conditions and wearing the same light clothing before and after each test to calculate the water loss through sweat during exercise. Participants urinated immediately before their weight was recorded and immediately after the exercise tests.

The following hydration protocols were used:

- Nonrehydration tests (NH1 and NH2): no rehydration during the exercise tests followed by $2 \mathrm{~h}$ of controlled rehydration after the tests were finished. Rehydration was performed with water in the $\mathrm{NH} 1$ test and with an isotonic sports drink in the $\mathrm{NH} 2$ test.

- Rehydration tests (H1 and H2): rehydration was performed during the exercise tests with $250 \mathrm{~mL}$ of water in the $\mathrm{H} 1$ test and a sports drink (distributed in two doses of $125 \mathrm{~mL}$ in minute 15 and minute 30) in the $\mathrm{H} 2$ test. After finishing the exercise tests, participants followed $2 \mathrm{~h}$ of a controlled rehydration protocol with water in the $\mathrm{H} 1$ test and a sports drink in the $\mathrm{H} 2$ test. The drinking volume during the 2-h controlled rehydration protocol was the same as the weight lost during exercise, which was individually measured in each participant in each of the four tests. The weight loss was calculated by subtracting the initial body weight from the final body weight. The difference in grams was considered as a volume in millilitres. Half of the amount was drunk during the first hour, and the remaining half was drunk at regular intervals during the second hour. After the rehydration protocol, participants were instructed to continue rehydration by drinking $50 \%$ of the lost-weight volume to ensure $150 \%$ of the weight lost was replaced.

Drink composition: Table 1 shows the composition of the drinks.

Table 1 Drink's composition

\section{Standardization of previous and subsequent diet and exercise}

To standardise the results, participants were instructed not to perform strenuous exercise in the $24 \mathrm{~h}$ prior to testing and not to eat any food or drink coffee or caffeinated beverages in the $2 \mathrm{~h}$ before the tests. To ensure euhydration before each trial, subjects followed a standardised hydration protocol by consuming an average of $350 \mathrm{~mL}$ of water $2 \mathrm{~h}$ before testing in accordance with the American College of Sports Medicine (ACSM) recommendations (Sawka et al. 2007).

After $2 \mathrm{~h}$ of controlled rehydration, participants followed specific dietary guidelines for the next $24 \mathrm{~h}$ :

- Carbohydrates: $8 \mathrm{~g} / \mathrm{kg}$.

- Proteins: $1.5 \mathrm{~g} / \mathrm{kg}$.

- Fat: avoid intake of fat.

- Milk or dairy products: not fortified with vitamins.

- Liquids: water-24 $\mathrm{h}$ after tests (min 50\% of total weight lost).

\section{Blood samples processing}

Blood samples $(10 \mathrm{~mL})$ were collected immediately before exercise (pre0), immediately after exercise (post0), at $2 \mathrm{~h}$, $6 \mathrm{~h}$, and $24 \mathrm{~h}$ after exercise tests.

The blood collection was performed by standard venipuncture on vacuum Vacutainer ${ }^{\circledR}$ tubes. Tubes were placed on ice immediately and after clot formation samples were centrifuged during $10 \mathrm{~min}$ at $3000 \mathrm{rpm}$. Serum was distributed and stored at $-80^{\circ} \mathrm{C}$ until processing.

Serum tHcy was determined using an enzymatic assay (AU400 analyser, Beckman Instruments, Ltd., Bucks, UK; $\mathrm{CV} \leq 6 \%$ ). Vitamin $\mathrm{B}_{12}$ was analysed using an electrochemiluminescence immnoassay (Elecsys 2010 analyser, Roche Diagnostics, IN, USA; CV $\leq 10 \%$ ). Serum Folate was determined using an electrochemiluminescence immunoassay (Elecsys 2010, Roche Diagnostics, IN, USA, CV $\leq 11 \%$ ). Creatinine was analysed using a colorimetric analyser (Beckman AU400, Beckman Instruments, Ltd., Bucks, $\mathrm{UK} ; \mathrm{CV} \leq 2 \%$ ) and creatine was determined by capillary

\begin{tabular}{lc}
\hline Bottled water & Sport drink \\
\hline Dry residue $265 \mathrm{mg} / \mathrm{L}$ & Ingredients: water, sucrose, salt and flavour- \\
Bicarbonates $276 \mathrm{mg} / \mathrm{L}$ & ings, stabilizers E-414 and E-445, E-133 dye, \\
Sulfates $6.9 \mathrm{mg} / \mathrm{L}$ & acidulant citric acid, sodium citrate minerals, \\
Chlorides $4.3 \mathrm{mg} / \mathrm{L}$ & potassium citrate, magnesium chloride \\
Calcium $90.4 \mathrm{mg} / \mathrm{L}$ & Energy value (values for each $100 \mathrm{~mL}): 31 \mathrm{kcal} ;$ \\
Magnesium $2.7 \mathrm{mg} / \mathrm{L}$ Sodium $2.1 \mathrm{mg} / \mathrm{L}$ & proteins $0 \mathrm{~g}$; carbohydrates $7.5 \mathrm{~g}$, which sugar \\
& added: $7.5 \mathrm{~g}$; fat 0 g, which saturated fatty \\
& acids: 0 g; dietary fiber $0 \mathrm{~g} ;$ sodium $0.05 \mathrm{~g} ;$ \\
& added minerals: chloride $4.7 \mathrm{mg}$; potassium \\
& $5.3 \mathrm{mg}$; magnesium $1.6 \mathrm{mg}$ \\
\hline
\end{tabular}


electrophoresis using a diode array detector (P/ACE Beckman, Fullerton, CA, USA) as described by Zinellu et al. (2006).

Serum sodium, chloride and magnesium were measured by indirect potentiometry technique (Beckman AU400, Beckman Instruments, Ltd., Bucks, UK). The rest of the routine biochemistry analysis was carried out with the colorimetric analyser (Beckman AU400, Beckman Instruments, Ltd., Bucks, UK CV $\leq 6 \%$ ) using standard methodologies. Urine osmolarity was determined by freezing point depression with the osmometer Osmo Station OM-6050 (Menarini Diagnostics, Florence, Italy, CV $\leq 1 \%$ ).

For hematological parameters, a complete hematological analysis was performed within the first hour after blood collection and was obtained by an automated hematology analyser (Celltac E MEK-7222 J/K, Nihon Kohden Corporation, Tokyo, Japan) at the Laboratory of the Faculty of Physical Activity and Sport Sciences-INEF, of the Technical University of Madrid (Laboratory number 242, Laboratory Network of the Region of Madrid).

The analysis of all the biochemical parameters was carried out at the Clinical laboratory of the Sports Medicine Center of the High Sports Council (HSC, Spain). Creatine was measured at the Clinical laboratory of the Faculty of Medicine, Department of Biomedical Sciences of University of Sassari (Sardinia, Italy).

\section{Haemoconcentration corrections}

To control the haemoconcentration by changes in plasma volume $(\Delta \mathrm{PV})$ during exercise and rehydration, this study presents data with and without corrections for concentrations, which were calculated using the Dill and Costill (1974) equation using haematocrit (Hct) (\%) and haemoglobin $(\mathrm{Hb})$ in $\mathrm{g} / \mathrm{dL}$.

$$
\begin{aligned}
\Delta \mathrm{PV}(\%)= & 100 \times[(\mathrm{Hb} \text { pre } / \mathrm{Hb} \text { post }) \\
& \times(100-\mathrm{Htc} \text { post }) /(100-\mathrm{Htc} \text { pre })-1],
\end{aligned}
$$

The correction for haemoconcentration of the biochemical parameters immediately after exercise, at $2 \mathrm{~h}, 6 \mathrm{~h}$ and $24 \mathrm{~h}$ were as follows (Alis et al. 2015):

Parameter $_{\mathrm{C}}=$ Parameter $_{\mathrm{U}} /(1-\Delta \mathrm{VP}(\%) / 100)$, where "C" and " $U$ " sub-indices denote "Corrected" and "Uncorrected" concentrations, respectively.

\section{Genetic analysis}

Whole blood $(5 \mathrm{~mL})$ from each participant was collected in ethylene-diaminetetraacetic acid, EDTA and sent to the Laboratory of Pediatrics, Faculty of Medicine, University of Cantabria. DNA was extracted from each sample using the
"QIAamp ${ }^{\circledR}$ DNA Blood Mini Kit" from QIAGEN (Hilden, Germany) and the genotyping was performed afterwards. The DNA samples were preserved at $-20^{\circ} \mathrm{C}$.

The analysis of the MTHFR C677T (rs1801133) polymorphism was done based on the PCR and RFLP techniques (Frosst et al. 1995).

\section{Statistical analysis}

All of the variables followed a normal distribution, therefore, parametric tests were used. Standard statistical methods were used to calculate the means and standard deviation (SD). Two-way analysis of variance for repeated measures (ANOVA) was used to determine differences in each variable between points (Pre0, Post0, $2 \mathrm{~h}, 6 \mathrm{~h}$ and $24 \mathrm{~h}$ ) and among tests (NH1, NH2, H1 and H2). Multiple evaluations were made using the Bonferroni post hoc test. The percentage change was calculated within each liquid between points (Pre0, Post0, $2 \mathrm{~h}, 6 \mathrm{~h}$ and $24 \mathrm{~h}$ ) for the tHcy variable.

Correlation analysis was made using Pearson correlation coefficient to check the relationship among the analysed variables.

All the parameters were corrected by haemoconcentration following the calculations described previously.

Differences in Systolic blood pressure, weight and urine osmolarity at pre 0 and post0 were analysed using Student $t$ test.

The interaction of MTHFR polymorphisms on tHcy, was analysed using a univariate model followed by a Kruskal-Wallis tests due to the small sample size in each genotype group.

A value of $P<0.05$ was considered statistically significant.

SPSS v.20.0 for Windows (IBM SPSS, Version 20.0. Armonk, NY: IBM Corp.) was used for the statistical analysis.

\section{Results}

Table 2 shows the general characteristics and genotypes of the study cohort and the distributions of the C677T MTHFR genotype. Concentrations of tHcy were not different among the C677T MTHFR genotype groups at any sampling point (data not shown).

The physiological parameters registered during the tests, including heart rate and blood pressure stratified by the four exercise tests, are shown in Table 3. Urine osmolarity before and after the tests and weight loss are shown in Table 4 . There were no statistical differences in osmolarity before and after the exercise tests. Weight loss during the exercise tests was significant in the four tests $(P<0.001)$. 
Table 2 Anthropometric characteristics and genotype of the studied sample

\begin{tabular}{llc}
\hline Characteristics & $\overline{\mathbf{X}}$ & SD \\
\hline Age (year) & 29.4 & 7.903 \\
Height (cm) & 176.0 & 7.163 \\
Weight (kg) & 76.1 & 7.854 \\
Body mass index (BMI) & 24.4 & 1.909 \\
Basal metabolism (Kcal) & 1960 & 167.7 \\
Fat mass (kg) & 11.3 & 4.184 \\
\% fat & 8.8 & 3.644 \\
Lean mass (kg) & 67.3 & 5.842 \\
Total body water (kg) & 49.3 & 4.281 \\
\hline Polymorphism & Genotype & $\%(n)$ \\
\hline MTHFR C677T & CC & $50 \%(10)$ \\
& CT & $45 \%(9)$ \\
\hline
\end{tabular}

MTHFR methylene tetrahydrofolate reductase polymorphism, CC genotype without mutation, CT genotype heterozygous, TT genotype MTHFR C677T common mutation

Table 3 Heart rate and blood pressure before and after the exercise tests

\begin{tabular}{lcccc}
\hline & NH1 & NH2 & H1 & H2 \\
\hline Systolic blood pressure pre0 (mmHg) & $121.11 \pm 6.46$ & $124.30 \pm 5.75$ & $116.50 \pm 9.52$ & 118.708 .90 \\
Systolic blood pressure post0 (mmHg) & $139.60 \pm 12.21^{* *}$ & $131.11 \pm 16.53$ & $127.22 \pm 10.60^{* *}$ & $125.83 \pm 10.67$ \\
Diastolic blood pressure pre0 (mmH) & $66.83 \pm 7.22$ & $69.15 \pm 4.68$ & $67.70 \pm 7.18$ & $70.35 \pm 7.54$ \\
Diastolic blood pressure post0 (mmHg) & $68.30 \pm 7.79$ & $65.05 \pm 7.22$ & $64.44 \pm 5.60$ & $65.88 \pm 8.32$ \\
HR max (bpm) & $174 \pm 23$ & $174 \pm 16$ & $162 \pm 13$ & $164 \pm 14$ \\
HR mean (bpm) & $153 \pm 14$ & $151 \pm 15$ & $140 \pm 12$ & $141 \pm 13$ \\
\hline
\end{tabular}

PreO before exercise, Post $\mathrm{O}$ immediately after exercise, $\mathrm{NH} 1$ non-hydration during exercise and water hydration after exercise, $\mathrm{NH} 2$ non-hydration during exercise and sport drink hydration after exercise, $H I$ water hydration during and after exercise, $H 2$ sport drink hydration during and after exercise

**Significant differences between previous point within each test $(P<0.001)$

Table 4 Weight lost and urine osmolarity before and after exercise

\begin{tabular}{lllll}
\hline & $\mathrm{NH} 1$ & $\mathrm{NH} 2$ & $\mathrm{H} 1$ & $\mathrm{H} 2$ \\
& $(\bar{X} \pm \mathrm{SD})$ & $(\bar{X} \pm \mathrm{SD})$ & $(\bar{X} \pm \mathrm{SD})$ & $(\bar{X} \pm \mathrm{SD})$ \\
\hline Weight lost after tests $(\mathrm{kg})$ & $1.31 \pm 0.37 * *$ & $1.39 \pm 0.29 * *$ & $1.20 \pm 0.32 * *$ & $1.08 \pm 0.34 * *$ \\
Osmolarity Pre0 $(\mathrm{mosm} / \mathrm{L})$ & $596.2 \pm 310.3$ & $666.5 \pm 309$ & $581.4 \pm 329.1$ & $747.2 \pm 240.5$ \\
Osmolarity Post0 $(\mathrm{mosm} / \mathrm{L})$ & $583.9 \pm 303.9$ & $670.6 \pm 294.4$ & $516.9 \pm 285$ & $674.1 \pm 269.1$ \\
\hline
\end{tabular}

PreO before exercise, Post $\mathrm{O}$ immediately after exercise, $\mathrm{NH} 1$ non-hydration during exercise and water hydration after exercise, $\mathrm{NH} 2$ non-hydration during exercise and sport drink hydration after exercise, $\mathrm{H} 1$ water hydration during and after exercise, $H 2$ sport drink hydration during and after exercise

**Significant differences between previous point within each test $(P<0.001)$
Table 5 shows the descriptive data as mean \pm SD of plasma volume change (\%) after the tests. The tHcy concentrations, corrected and uncorrected for haemoconcentration at all measured points in the four tests, are shown in Table 6. Mean Hcy values $>10 \mu \mathrm{mol} / \mathrm{L}$ were observed after the tests at all measured points. Uncorrected serum tHcy concentrations were significantly increased $(P<0.05)$ after acute aerobic exercise in the NH1 and $\mathrm{NH} 2$ tests [mean increase \pm SD: $1.55 \pm 0.33(15.18 \%)$ and $1.76 \pm 0.25$ $(17.69 \%) \mu \mathrm{mol} / \mathrm{L}$, respectively], while no significant differences were found in the $\mathrm{NH} 1$ and $\mathrm{NH} 2$ tests. Conversely, corrected tHcy concentrations increased over time from Pre0 and reached their maximum values at $6 \mathrm{~h}(P<0.05)$, representing an increase of $18.90 \%$ and $21.21 \%$ for the NH1 
Table 5 Change of plasma volume (\%) after all four tests

\begin{tabular}{lcrrr}
\hline \multirow{4}{*}{\multicolumn{4}{l}{$\Delta \mathrm{VP}(\%) \bar{X} \pm \mathrm{SD}$}} & \multicolumn{3}{l}{$\mathrm{H} 1$} & \multicolumn{1}{l}{$\mathrm{H} 2$} \\
\cline { 2 - 5 } & \multicolumn{1}{l}{$\mathrm{NH} 1$} & $\mathrm{NH} 2$ & $-8.45 \pm 8.79$ & $-9.69 \pm 5.57$ \\
\hline Post0 & $-7.82 \pm 5.28$ & $-10.77 \pm 3.36$ & $-4.98 \pm 9.27$ & $3.53 \pm 5.82$ \\
$2 \mathrm{~h}$ & $1.57 \pm 8.17$ & $2.86 \pm 6.15$ & $-02 \pm 7.17$ & $7.25 \pm 8.37$ \\
$6 \mathrm{~h}$ & $4.92 \pm 10.71$ & $4.51 \pm 8.15$ & 1.02 & \\
$24 \mathrm{~h}$ & $3.87 \pm 9.93$ & $0.49 \pm 12.31$ & $0.60 \pm 8.47$ & $2.75 \pm 7.45$ \\
\hline
\end{tabular}

Post 0 immediately after exercise, $2 h 2 \mathrm{~h}$ after exercise, $6 h 6 \mathrm{~h}$ after exercise, $24 h 24 \mathrm{~h}$ after exercise, $\mathrm{NH} 1$ non-hydration during exercise and water hydration after exercise, $\mathrm{NH} 2$ non-hydration during exercise and sport drink hydration after exercise, $H 1$ water hydration during and after exercise, $H 2$ sport drink hydration during and after exercise

and $\mathrm{NH} 2$ tests, respectively. No significant changes were found at any of the measured points in the $\mathrm{H} 1$ and $\mathrm{H} 2$ tests. After the $2 \mathrm{~h}$ postexercise rehydration protocol, corrected tHcy concentrations showed a tendency to increase (NS) and reached their maximum values at $6 \mathrm{~h}$, with a $6.20 \%$ and $14 \%$ increase from Pre0 for $\mathrm{H} 1$ and $\mathrm{H} 2$, respectively. At $24 \mathrm{~h}$, tHcy concentrations recovered to the baseline value in each of the four tests. Table 7 presents the concentrations of folate and vitamin $\mathrm{B}_{12}$, and Table 8 presents the concentrations of creatinine and creatine corrected and uncorrected for haemoconcentration during the tests. Compared with baseline, vitamin $\mathrm{B}_{12}$ values were significantly increased at $6 \mathrm{~h}$ in the NH1, NH2 and $\mathrm{H} 2$ tests. Conversely, no significant differences were observed in serum folate concentrations. Serum creatine concentrations significantly increased at Post0 in the four tests $(P<0.01$ in the NH1, NH2 and $\mathrm{H} 2$ tests, and $P<0.05$ in the $\mathrm{H} 1$ test) and decreased at $2 \mathrm{~h}$ in the four tests $(P<0.05$ in the NH1, NH2 and $\mathrm{H} 2$ tests). The highest creatine concentrations were observed at $6 \mathrm{~h}$ in the four tests $(P<0.05)$. No significant differences were observed in serum creatinine at Post 0 in any of the tests. Moreover, creatinine also significantly increased to its maximum values in all four tests at $6 \mathrm{~h}(P<0.05)$.

\section{Discussion}

To the best of the author's knowledge, this is the first investigation to analyse the effects of a controlled rehydration protocol on tHcy concentrations during and after acute exercise. The exact mechanisms by which serum tHcy increases are still unknown (Deminice and Jordao 2012). Some authors have speculated that haemoconcentration could explain some of the increased tHcy after acute exercise (Herrmann et al. 2003b). To approximate whether haemoconcentration is the reason behind the tHcy increase after acute exercise, both corrected and uncorrected tHcy concentration data were analysed. Uncorrected tHcy data were significantly elevated immediately after exercise without rehydration $(P<0.05)$, while corrected tHcy concentrations at the same point showed the same tendency. This may demonstrate that part of the Hcy increase is due to haemoconcentration, while the other part is due to mechanisms involved in the effects of exercise. Thus, it is important to establish and differentiate the proper use of the methodological haemoconcentration corrections depending on the research aim in the exercise context. Research that aims to study the kinetics and mechanisms underlying the physiological behaviour of specific parameters should include haemoconcentration corrections. Conversely, research that aims to analyse an existing risk relating to specific moments of dehydration-induced haemoconcentration should not include haemoconcentration corrections to study the 'real concentration' in the blood.

Table 6 Total homocysteine concentrations corrected (C) and uncorrected (U) by hemoconcentration

\begin{tabular}{|c|c|c|c|c|c|c|c|c|}
\hline \multirow[t]{2}{*}{$(\mu \mathrm{mol} / \mathrm{L})$} & \multicolumn{2}{|l|}{ NH1 } & \multicolumn{2}{|l|}{$\mathrm{NH} 2$} & \multicolumn{2}{|l|}{$\mathrm{H} 1$} & \multicolumn{2}{|l|}{$\mathrm{H} 2$} \\
\hline & THcy U & THcy C & THcy U & THcy C & THcy U & THcy C & THcy U & THcy C \\
\hline Pre0 & $10.21 \pm 1.44$ & $10.21 \pm 1.44$ & $9.95 \pm 1.65$ & $9.95 \pm 1.65$ & $10.33 \pm 1.94$ & $10.33 \pm 1.94$ & $10.36 \pm 1.96$ & $10.36 \pm 1.96$ \\
\hline Post0 & $11.76 \pm 2.33 * *$ & $10.90 \pm 2.01^{\mathrm{b}}$ & $11.71 \pm 1.69^{* *}$ & $10.65 \pm 1.47^{\mathrm{b}}$ & $10.98 \pm 2.26$ & $10.12 \pm 1.89^{b}$ & $11.26 \pm 1.72$ & $10.41 \pm 1.60^{\mathrm{b}}$ \\
\hline $2 \mathrm{~h}$ & $11.29 \pm 2.14$ & $11.54 \pm 2.27^{\mathrm{a}}$ & $10.63 \pm 1.95^{*}$ & $10.96 \pm 2.00^{\mathrm{b}}$ & $10.59 \pm 2.09$ & $10.19 \pm 2.32^{b}$ & $9.81 \pm 1.76$ & $10.30 \pm 1.94^{b}$ \\
\hline $6 \mathrm{~h}$ & $11.36 \pm 1.89^{\mathrm{a}}$ & $12.14 \pm 2.60^{* a, b}$ & $11.43 \pm 1.95$ & $12.06 \pm 2.26^{\mathrm{a}, \mathrm{b}}$ & $10.80 \pm 1.89$ & $10.97 \pm 2.03$ & $10.78 \pm 2.37$ & $11.81 \pm 2.24^{b}$ \\
\hline $24 \mathrm{~h}$ & $10.14 \pm 1.51^{* *}$ & $10.68 \pm 2.10$ & $10.72 \pm 1.28$ & $11.11 \pm 2.43$ & $10.29 \pm 2.15$ & $10.49 \pm 2.34$ & $10.40 \pm 1.65$ & $10.81 \pm 1.45$ \\
\hline
\end{tabular}

$t H c y$ total serum homocysteine, PreO before exercise, Post $O$ immediately after exercise, $2 h 2 \mathrm{~h}$ after exercise, $6 h 6 \mathrm{~h}$ after exercise, $24 h 24 \mathrm{~h}$ after exercise, $\mathrm{NH} 1$ non-hydration during exercise and water hydration after exercise, $\mathrm{NH} 2$ non-hydration during exercise and sport drink hydration after exercise, $\mathrm{Hl}$ water hydration during and after exercise, $H 2$ sport drink hydration during and after exercise, $C$ corrected by hemoconcentration, $U$ uncorrected by hemoconcentration

*Significant differences from previous point within each test $(P<0.05)$

**From previous point within each test $(P<0.001)$

${ }^{\mathrm{a}}$ From baseline within each test $(P<0.05)$

${ }^{\mathrm{b}}$ Differences between same point $\mathrm{C}$ and $\mathrm{U}$ 
Table 7 Folate and vitamin $\mathrm{B}_{12}$ concentrations corrected and uncorrected by hemoconcentration

\begin{tabular}{|c|c|c|c|c|c|c|c|c|}
\hline \multirow[t]{2}{*}{$(\mathrm{ng} / \mathrm{mL})$} & \multicolumn{2}{|l|}{ NH1 } & \multicolumn{2}{|l|}{$\mathrm{NH} 2$} & \multicolumn{2}{|c|}{ H1 } & \multicolumn{2}{|l|}{$\mathrm{H} 2$} \\
\hline & $\begin{array}{l}\frac{\text { Folate U }}{X} \pm \mathrm{SD}\end{array}$ & $\begin{array}{l}\frac{\text { Folate C }}{X} \pm \mathrm{SD}\end{array}$ & $\begin{array}{l}\frac{\text { Folate U }}{X} \pm \mathrm{SD}\end{array}$ & $\begin{array}{l}\text { Folate C } \\
X \pm S D\end{array}$ & $\begin{array}{l}\text { Folate U } \\
X \pm S D\end{array}$ & $\begin{array}{l}\text { Folate C } \\
X \pm \mathrm{SD}\end{array}$ & $\begin{array}{l}\text { Folate U } \\
X \pm S D\end{array}$ & $\begin{array}{l}\text { Folate C } \\
X \pm S D\end{array}$ \\
\hline Pre0 & $8.89 \pm 3.34$ & $8.89 \pm 3.34$ & $9.04 \pm 3.37$ & $9.04 \pm 3.37$ & $8.85 \pm 1.84$ & $8.85 \pm 1.84$ & $8.88 \pm 2.78$ & $8.88 \pm 2.78$ \\
\hline Post0 & $10.40 \pm 2.59$ & $9.67 \mathrm{~b} \pm 2.46$ & $10.87 \pm 3.32 *$ & $9.94 \pm 3.08^{\mathrm{b}}$ & $10.03 \pm 3.11$ & $9.22 \pm 2.69^{b}$ & $10.37 \pm 3.44 * *$ & $9.24 \pm 3.11^{\mathrm{b}}$ \\
\hline $2 \mathrm{~h}$ & $9.67 \pm 3.21$ & $9.85 \pm 3.08$ & $8.92 \pm 2.50 * *$ & $9.24 \pm 2.74^{\mathrm{b}}$ & $10.10 \pm 2.65^{a, c}$ & $9.70 \pm 2.84$ & $9.69 \pm 4.26$ & $9.92 \pm 4.53^{\mathrm{b}}$ \\
\hline $6 \mathrm{~h}$ & $9.05 \pm 2.43$ & $9.62 \pm 2.42^{\mathrm{b}}$ & $9.20 \pm 2.65$ & $9.63 \pm 2.62^{\mathrm{b}}$ & $9.45 \pm 2.13$ & $9.55 \pm 2.14$ & $9.58 \pm 2.92$ & $10.13 \pm 3.16^{\mathrm{b}}$ \\
\hline $24 \mathrm{~h}$ & $9.00 \pm 2.59$ & $9.33 \pm 2.30$ & $9.17 \pm 3.38$ & $9.33 \pm 3.56$ & $8.69 \pm 2.33$ & $8.70 \pm 2.53$ & $8.96 \pm 2.76$ & $9.26 \pm 3.01$ \\
\hline$(\mathrm{pg} / \mathrm{mL})$ & $\begin{array}{l}\frac{\text { Vitamin } \mathrm{B}_{12} \mathrm{U}}{X} \pm \mathrm{SD} \\
\end{array}$ & $\begin{array}{l}\mathrm{Vitamin}^{\mathrm{B}} \mathrm{B}_{12} \mathrm{C} \\
\mathrm{SD}\end{array}$ & $\frac{\text { Vitamin } B_{12} \mathrm{U}}{X \pm S D}$ & $\frac{V_{i t a m i n} B_{12} C}{X}$ & $\begin{array}{l}\mathrm{Vitamin}_{\mathrm{B}} \mathrm{B} \mathrm{U} \\
\mathrm{SD}\end{array}$ & $\begin{array}{l}\underline{\text { Vitamin }}_{\mathrm{B}_{12} \mathrm{C}} \\
X \mathrm{SD}\end{array}$ & $\begin{array}{l}\underline{V i t a m i n} \mathrm{~B}_{12} \mathrm{U} \\
\mathrm{SD}\end{array}$ & $\frac{V \text { itamin } B_{12} C}{X \pm S D}$ \\
\hline Pre0 & $458.22 \pm 154.82$ & $458.22 \pm 154.82$ & $473.65 \pm 167.91$ & $473.65 \pm 167.91$ & $465.60 \pm 165.39$ & $465.60 \pm 165.39$ & $479.62 \pm 180.93$ & $479.62 \pm 180.93$ \\
\hline Post0 & $522.58 \pm 173.47^{*}$ & $484.46 \pm 157.04^{\mathrm{b}}$ & $513.75, \mathrm{~b} \pm 174.19^{* *}$ & $\begin{array}{ll}* * & 469.20 \pm 159.95\end{array}$ & $510.69 \pm 162.67^{\mathrm{b}}$ & b $\quad 472.64 \pm 152.39^{\mathrm{b}}$ & b $\quad 561.75 \pm 230.42$ & $509.63 \pm 219.32$ \\
\hline $2 \mathrm{~h}$ & $505.07 \pm 160.32$ & $513.86 \pm 149.34$ & $475.77 \pm 153.63^{*, \mathrm{~b}}$ & $*, \mathrm{~b} \quad 495.30 \pm 179.97$ & $504.43 \pm 181.45$ & $486.55 \pm 193.27^{\mathrm{b}}$ & b $\quad 498.04 \pm 199.13$ & $512.47 \pm 221.1$ \\
\hline $6 \mathrm{~h}$ & $514.51 \pm 207.65$ & $543.03 \pm 184.75^{*, \mathrm{a}}$ & $510.53 \pm 179.61^{*, a}$ & $*, \mathrm{a} \quad 536.02 \pm 181.22^{\mathrm{a}}$ & a $\quad 494.59 \pm 173.12$ & $498.97 \pm 166.74^{\mathrm{b}}$ & b $\quad 514.58 \pm 183.30$ & $558.51 \pm 246.12^{\mathrm{a}}$ \\
\hline $24 \mathrm{~h}$ & $483.55 \pm 185.20^{*}$ & $=503.95 \pm 179.40$ & $500.04 \pm 198.52$ & $506.55 \pm 187.42 *$ & $* \quad 487.01 \pm 165.41$ & $507.15 \pm 198.25$ & $525.10 \pm 191.28$ & $547.30 \pm 236.93^{\mathrm{a}}$ \\
\hline
\end{tabular}

tHcy total serum homocysteine, PreO before exercise, Post 0 immediately after exercise, $2 h 2 \mathrm{~h}$ after exercise, $6 h 6 \mathrm{~h}$ after exercise, $24 h 24 \mathrm{~h}$ after exercise, $\mathrm{NH} 1$ non-hydration during exercise and water hydration after exercise, $\mathrm{NH} 2$ non-hydration during exercise and sport drink hydration after exercise, $H 1$ water hydration during and after exercise, $H 2$ sport drink hydration during and after exercise, $C$ corrected by hemoconcentration, $U$ uncorrected by hemoconcentration

*Significant differences from previous point within each test $(P<0.05)$

**From previous point within each test $(P<0.001)$

${ }^{a}$ From baseline within each test $(P<0.05)$

${ }^{\mathrm{b}}$ Differences between same point $\mathrm{C}$ and $\mathrm{U}(P<0.05)$

${ }^{c}$ Differences with test $\mathrm{NH} 2$ at same point $(P<0.05)$

Table 8 Creatine and creatinine concentrations corrected and uncorrected by hemoconcentration

\begin{tabular}{|c|c|c|c|c|c|c|c|c|}
\hline \multirow[t]{2}{*}{$(\mathrm{mg} / \mathrm{dL})$} & \multicolumn{2}{|l|}{$\mathrm{NH} 1$} & \multicolumn{2}{|l|}{$\mathrm{NH} 2$} & \multicolumn{2}{|l|}{$\mathrm{H} 1$} & \multicolumn{2}{|l|}{$\mathrm{H} 2$} \\
\hline & $\begin{array}{l}\text { Creatine U } \\
\bar{X} \pm \mathrm{SD}\end{array}$ & $\begin{array}{l}\text { Creatine C } \\
X_{ \pm} \text {SD }\end{array}$ & $\begin{array}{l}\text { Creatine U } \\
\bar{X} \pm \mathrm{SD}\end{array}$ & $\begin{array}{l}\text { Creatine C } \\
X_{ \pm} \text {SD }\end{array}$ & $\begin{array}{l}\text { Creatine U } \\
X_{ \pm} \mathrm{SD}^{-}\end{array}$ & $\begin{array}{l}\text { Creatine C } \\
X_{ \pm} \text {SD }\end{array}$ & $\begin{array}{l}\text { Creatine U } \\
\bar{X} \pm \mathrm{SD}\end{array}$ & $\begin{array}{l}\text { Creatine C } \\
X_{ \pm} \text {SD }\end{array}$ \\
\hline Pre0 & $2.68 \pm 1.19$ & $2.68 \pm 1.19$ & $2.53 \pm 0.91$ & $2.53 \pm .91$ & $2.73 \pm 1.13$ & $2.73 \pm 1.13$ & $2.59 \pm 1.15$ & $2.59 \pm 1.15$ \\
\hline Post0 & $3.66 \pm 1.35^{* *}$ & $3.41 \pm 1.30^{* *, b}$ & $3.67 \pm 1.65^{* *}$ & $3.41 \pm 1.43^{*, \mathrm{a}, \mathrm{b}}$ & $3.37 \pm 1.17^{*}$ & $3.13 \pm 1.12^{*, \mathrm{~b}}$ & $3.87 \pm 1.70^{* *}$ & $3.56 \pm 1.63^{*, \mathrm{~b}}$ \\
\hline $2 \mathrm{~h}$ & $2.42 \pm 0.94 * *$ & $2.47 * \pm .97$ & $2.61 \pm 1.02 *$ & $2.70 \pm 1.12^{*, \mathrm{~b}}$ & $2.32 \pm 0.83 *$ & $2.23 \pm .82 *$ & $2.54 \pm 1.34 * *$ & $2.70 \pm 1.59^{*, \mathrm{~b}}$ \\
\hline $6 \mathrm{~h}$ & $4.50 \pm 2.99^{*, \mathrm{a}}$ & $4.76 \pm 3.14^{*, a, b}$ & $3.91 \pm 2.30^{\mathrm{a}}$ & $4.12 \pm 2.37^{\mathrm{a}, \mathrm{b}}$ & $3.90 \pm 2.38$ & $3.93 \pm 2.39 *$ & $4.59 \pm 3.58^{*}$ & $5.12 \pm 4.03^{*, \mathrm{a}, \mathrm{b}}$ \\
\hline $24 \mathrm{~h}$ & $2.49 \pm 1.00 *$ & $2.59 \pm 1.01^{*}$ & $2.73 \pm 1.12$ & $2.92 \pm 1.76$ & $2.81 \pm 1.44$ & $2.86 \pm 1.46$ & $2.66 \pm 1.18$ & $2.78 \pm 1.23$ \\
\hline$(\mathrm{mg} / \mathrm{dL})$ & Creatinine U & Creatinine $\mathrm{C}$ & Creatinine U & Creatinine $\mathrm{C}$ & Creatinine U & Creatinine $\mathrm{C}$ & Creatinine U & Creatinine $\mathrm{C}$ \\
\hline Pre0 & $1.13 \pm 0.13$ & $1.13 \pm 0.13$ & $1.13 \pm 0.08$ & $1.13 \pm 0.08$ & $1.08 \pm 0.10$ & $1.08 \pm 0.10$ & $1.14 \pm 0.10$ & $1.14 \pm 0.10$ \\
\hline Post0 & $1.27 \pm 0.13 * *$ & $1.18 \pm 0.13^{\mathrm{b}}$ & $1.26 \pm 0.14 * *$ & $1.13 \pm 0.13^{b}$ & $1.20 \pm 0.15^{*}$ & $1.11 \pm 0.13^{\mathrm{b}}$ & $1.24 \pm 0.14 *$ & $1.14 \pm 0.13^{\mathrm{b}}$ \\
\hline $2 \mathrm{~h}$ & $1.16 \pm 0.11^{* *}$ & $1.19 \pm 0.15$ & $1.15 \pm 0.09 * *$ & $1.19 \pm 0.14^{\mathrm{b}}$ & $1.13 \pm 0.13^{\mathrm{a}}$ & $1.09 \pm 0.17^{b}$ & $1.14 \pm 0.15^{*}$ & $1.19 \pm 0.17^{b}$ \\
\hline $6 \mathrm{~h}$ & $1.21 \pm 0.20$ & $1.28 \pm 0.25^{\mathrm{a}, \mathrm{b}}$ & $1.18 \pm 0.14$ & $1.24 \pm 0.17^{\mathrm{a}, \mathrm{b}}$ & $1.19 \pm 0.15^{\mathrm{a}}$ & $1.21 \pm 0.16^{*, \mathrm{a}}$ & $1.18 \pm 0.10$ & $1.29 \pm 0.19^{\mathrm{a}, \mathrm{b}}$ \\
\hline $24 \mathrm{~h}$ & $1.11 \pm 0.09$ & $1.16 \pm 0.15$ & $1.11 \pm 0.10$ & $1.13 \pm 0.18^{*}$ & $1.13 \pm 0.10^{\mathrm{a}}$ & $1.14 \pm 0.15$ & $1.13 \pm 0.12$ & $1.16 \pm 0.18^{*}$ \\
\hline
\end{tabular}

$t H c y$ total serum homocysteine, Pre 0 before exercise, Post 0 immediately after exercise, $2 h 2 \mathrm{~h}$ after exercise, $6 h 6 \mathrm{~h}$ after exercise, $24 h 24 \mathrm{~h}$ after exercise, $\mathrm{NH} 1$ non-hydration during exercise and water hydration after exercise, $\mathrm{NH} 2$ non-hydration during exercise and sport drink hydration after exercise, $H 1$ water hydration during and after exercise, $H 2$ sport drink hydration during and after exercise, $C$ corrected by hemoconcentration, $U$ uncorrected by hemoconcentration

*Significant differences from previous point within each test $(P<0.05)$

**From previous point within each test $(P<0.001)$

${ }^{\mathrm{a}}$ From baseline within each test $(P<0.05)$

${ }^{\mathrm{b}}$ Differences between same point $\mathrm{C}$ and $\mathrm{U}(P<0.05)$

${ }^{\mathrm{c}}$ Differences between same point with $\mathrm{H} 1$ test $(P<0.05)$ 
With regards to the objectives of this study, serum tHcy concentrations during rehydration are discussed without the haemoconcentration correction. The results showed that rehydration during acute exercise at $65 \%$ of $\mathrm{VO}_{2}$ max maintained tHcy concentrations at baseline up to $2 \mathrm{~h}$ after exercise independent of the type of liquid (i.e. water or sports drink). Conversely, when exercise tests were performed without rehydration, tHcy concentrations increased significantly $(P<0.05)$ and reached values close to the cutoff point $(>12 \mu \mathrm{mol} / \mathrm{L})$ (Castañon et al. 2007). This data suggests that rehydration during aerobic submaximal exercise could have a protective effect on increased tHcy concentrations during and after acute exercise.

Some experimental studies have shown increased tHcy after acute exercise (Herrmann et al. 2003b; Konig et al. 2003; Real et al. 2005; Gelecek et al. 2007; Venta et al. 2009; Bizheh and Jaafari 2011; Deminice et al. 2011, 2013; Iglesias-Gutierrez et al. 2012). The results from this study showed higher tHcy concentrations immediately after acute aerobic submaximal exercise with a continued increase reaching maximum values at $6 \mathrm{~h}$ post-exercise. At $24 \mathrm{~h}$ after exercise, tHcy concentrations recovered to baseline values. In line with these results, Herrmann et al. (2003b) found a $64 \%$ increase after a marathon race. Conversely, Konig et al. (2003) found higher tHcy concentrations at $1 \mathrm{~h}$ after acute exercise; however, high tHcy concentrations were also observed at $24 \mathrm{~h}$ after a triathlon competition.

The rise in Hcy after acute exercise seems to be transitory and tends to return to baseline levels after $24 \mathrm{~h}$. Although the data from this study revealed an overall sample mean of $>10 \mu \mathrm{mol} / \mathrm{L}$ after acute exercise in all tests, this could indicate a relevant issue that should be studied carefully as there are no data available regarding the effects of transitory increased Hcy on health (Real et al. 2005). In addition, the observed Hcy increase induced by acute exercise was slight compared to that associated with pathological conditions such as CVD (Shi et al. 2015), chronic renal failure (Jakovljevic et al. 2015) and dementia (Kumudini et al. 2014; Shen and Ji 2015). Therefore, increased Hcy induced by acute exercise may not be considered a risk factor for cardiovascular events mediated by hyperhomocysteinaemia.

It is important to remember that this effect is different from the effects found in chronic exercise. Some researchers reported an exercise-induced reduction in tHcy after training (Randeva et al. 2002; Vincent et al. 2003, 2006; Choi et al. 2014), while other studies showed that training did not contribute to decreased tHcy concentrations (Boreham et al. 2005). Interestingly, Okura et al. (2006) found different responses depending on the baseline tHcy status; for example, increased tHcy levels were observed after training in subjects with normal tHcy concentrations at baseline, while the opposite effect (i.e. decreased tHcy after training) was observed in subjects with hyperhomocysteinaemia at baseline. Molina-López et al. (2013) and Guzel et al. (2012) also found increased tHcy levels after exercise training programs. Konig et al. (2003) concluded that although acute exercise significantly increased tHcy, chronic endurance exercise was not associated with higher plasma tHcy concentrations. In summary, acute exercise may induce an increase in tHcy levels. In contrast, no consensus exists regarding the training effect, as all the analysed investigations used a variety of exercise interventions with different intensities, durations and modes of exercise.

The parameters that influence tHcy concentrations and their implications with exercise should receive considerable attention. These factors include B vitamins, such as folate, vitamin $\mathrm{B}_{12}$ and vitamin $\mathrm{B}_{6}$ blood levels, as cofactors of several enzymes involved in Hcy metabolism. The inverse correlations of serum vitamin $\mathrm{B}_{12}$ and folate with tHcy are well established in the literature (González-Gross et al. 2002); however, this interaction may be modulated by exercise or training. The correlation of blood vitamin $B_{12}$ and folate with tHcy before exercise was observed in various studies; however, the results were less clear and sometimes controversial regarding exercise or training programs. The results showed an inverse correlation between folate and tHcy before exercise; however, this correlation was lost after exercise and hours later. In accordance with the results of this study, the literature shows a high variability in the correlations of folate and vitamin $B_{12}$ with tHcy concentrations (Maroto-Sanchez et al. 2016).

Folate and vitamin $B_{12}$ were increased after acute exercise, the same as previously found in the study of Iglesias-Gutierrez et al. (2012). There is a general consensus regarding increased folate and vitamin $\mathrm{B}_{12}$ levels after acute exercise, competition or training programs (Maroto-Sanchez et al. 2016). In addition, some authors have speculated that tHcy increases because vitamin $B_{6}$ levels are too low to reduce Hcy and convert it to cysteine via the transsulfuration pathway. It should be noted that vitamin $\mathrm{B}_{6}$ is required as a coenzyme for transaminases, decarboxylases and glycogen phosphorylate in metabolic pathways of energy production. Herrmann et al. (2003c) suggested that endurance athletes had a higher prevalence of $B$ vitamin deficiency due to the high necessity of vitamin $\mathrm{B}_{6}$ and folate not only during exercise but also during training, as vitamin $\mathrm{B}_{6}$ is necessary to fuel working muscles and to repair damaged tissues (Joubert and Manore 2006).

Creatine is responsible for a considerable level of S-adenosylmethionine consumption in the liver for Hcy formation. Evidence also suggests that physical activity may alter Hcy metabolism by increasing protein or methyl group turnover (Gibala 2001). During high-intensity exercise, creatine phosphate is required as an immediate energy source for muscle contraction. The increased demand for creatine synthesis is a key factor in the modulation of methyl balance and 
one of the most important factors related to increased tHcy (Sotgia et al. 2007). Results from the present investigation showed increased levels of creatine and creatinine after exercise, which reached the highest values at $6 \mathrm{~h}$ after exercise. These data support the idea of Sotgia et al. (2007), who suggested that creatine demand was increased after highintensity exercise as substrate utilisation and consequently increased the formation of tHcy. However, more studies are necessary to examine the activities of key enzymes in creatine synthesis after acute exercise and their association with tHcy concentrations.

Rehydration after exercise is a common and necessary routine for all athletes. As rehydration has an effect on restoring plasma volume, fluid losses and physiological systems are altered by acute exercise (Cheuvront and Kenefick 2014). The results showed that $2 \mathrm{~h}$ of a rehydration protocol with a sports drink after aerobic submaximal exercise significantly reduced the previous increase in tHcy concentration. Moreover, the same tendency was also observed for water although without a significant difference (NS).

After $2 \mathrm{~h}$ of the rehydration protocol, tHcy concentrations continued to be higher than at baseline in both the water and sports drink groups. The differences between the liquids could be due to the hydration effect of the carbohydrate sports drink. Drinking fluids that contain carbohydrates and electrolytes may offer a gradual return to the predehydration levels and prevent any decrease in circulating sodium concentration, thus better maintaining the plasma volume and resulting in a smaller urine fluid loss.

Some studies have highlighted the importance of avoiding a rapid increase in plasma volume and a corresponding reduction in sodium concentration and osmolarity during postexercise rehydration to ensure that diuresis does not occur and that the retention of ingested fluid is maximised (Evans et al. 2009). As rehydration with a sports drink (containing carbohydrates and electrolytes) helps to maintain plasma volume better than water, it is hypothesised that a sports drinks would be better than water at restoring elevated tHcy and other blood parameters that could be altered during exercise.

\section{Conclusion}

An adequate rehydration protocol during acute aerobic submaximal exercise with both water and a sports drink maintains tHcy concentrations at baseline and up to $2 \mathrm{~h}$ after acute exercise in physically active male adults. Furthermore, rehydration during exercise prevents a further increase in tHcy concentrations at $6 \mathrm{~h}$. This investigation demonstrated that part of the increase in tHcy levels during exercise was due to the haemoconcentration and that another part was due to the mechanisms involved in the effects of exercise. The effects of rehydration and exercise on tHcy concentrations after acute exercise require further investigation.

\section{Limitations and strengths of the study}

A few limitations of the present investigation are noteworthy. The small sample size means that the genetic profile can only be taken as a control measure. Moreover, the lack of strict dietary control at 6 and $24 \mathrm{~h}$ after the tests could complicate the interpretation of results at $6 \mathrm{~h}$ after exercise. We would also mention that transient increase of tHcy, partially consequent to short lasting dehydration, seems unlikely to become a significant indicator of a high $\mathrm{CV}$ risk profile. This seems particularly true, since the study population is made of physically active adult males, in the middle of their fourth decade of life, who do not appear to display any other significant $\mathrm{CV}$ risk factor in their cumulative profile.

Some strengths of the present investigation should also be mentioned. This study is the first to analyse the effects of a controlled rehydration protocol on total Hcy concentrations after acute aerobic submaximal exercise. It is also the first study to use a crossover design to analyse the effects of acute exercise with and without haemoconcentration corrections. Furthermore, this study will contribute to a better understanding of tHcy responses after acute exercise and the effects of hydration as an important component in restoring altered health-related biomarkers (i.e. Hcy in this case) that have not been measured to date. MTHFR was included as a control variable. Moreover, the inclusion of a standardised protocol, the strict following of the fieldwork, the homogeneity of the study sample and the control of all parameters during the experimental fieldwork at the laboratory must be mentioned.

Acknowledgements Authors would like to thank Rosa María Torres, Teresa Amigo, Javier Butragueño for laboratory work, Dr. Mercedes Galindo, Dr. Javier Calderón and Dr. Javier Rojo for the medical supervision of the study and Laura Barrios for advice in the statistical analysis of the data.

Funding The study has been financed with research funds of the ImFINE research group from the Universidad Politécnica de Madrid. Spain.

\section{Compliance with ethical standards}

Conflict of interest The authors declare no conflicts of interest.

Ethical approval All procedures performed in studies involving human participants were in accordance with the ethical standards of the institutional and/or national research committee and with the 1964 Helsinki declaration and its later amendments or comparable ethical standards. 
Informed consent Informed consent was obtained from all individual participants included in the study.

\section{References}

Alis R et al (2015) Hemoconcentration induced by exercise: revisiting the Dill and Costill equation. Scand J Med Sci Sports 25(6):e630-e637

Arnaoutis G et al (2017) The effect of hypohydration on endothelial function in young healthy adults. Eur J Nutr 56(3):1211-1217. https://doi.org/10.1007/s00394-016-1170-8

Bizheh N, Jaafari M (2011) The effect of a single bout circuit resistance exercise on homocysteine, hs-CRP and fibrinogen in sedentary middle aged men. Iran J Basic Med Sci 14:568

Boreham CA, Kennedy RA, Murphy MH, Tully M, Wallace WF, Young I (2005) Training effects of short bouts of stair climbing on cardiorespiratory fitness, blood lipids, and homocysteine in sedentary young women. Br J Sports Med 39:590-593

Boushey CJ, Berestford SA, Omenn GS, Motulsky AG (1995) A quantitative assessment of plasma homocysteine as a risk factor for cardiovascular disease. JAMA 274:1049-1057

Brosnan JT, Da Silva RP, Brosnan ME (2011) The metabolic burden of creatine synthesis. Amino Acids 40:1325-1331

Casa DJ et al (2000) National athletic trainers' association position statement: fluid replacement for athletes. J Athl Train 35:212-224

Castañon MM, Lauricella AM, Kordich L, Quintana I (2007) Plasma homocysteine cutoff values for venous thrombosis. Clin Chem Lab Med 45:232-236

Cheuvront SN, Kenefick RW (2014) Dehydration: physiology, assessment, and performance effects. Compr Physiol 4(1):257-285

Choi JK et al (2014) Regular exercise training increases the number of endothelial progenitor cells and decreases homocysteine levels in healthy peripheral blood. Korean J Physiol Pharmacol 18:163-168

Deminice R, Jordao AA (2012) Creatine supplementation reduces oxidative stress biomarkers after acute exercise in rats. Amino Acids 43:709-715. https://doi.org/10.1007/s00726-011-1121-x

Deminice R, Vannucchi H, Simoes-Ambrosio LM, Jordao AA (2011) Creatine supplementation reduces increased homocysteine concentration induced by acute exercise in rats. Eur J Appl Physiol 111:2663-2670. https://doi.org/10.1007/s00421-011-1891-6

Deminice R, Rosa FT, Franco GS, Jordao AA, de Freitas EC (2013) Effects of creatine supplementation on oxidative stress and inflammatory markers after repeated-sprint exercise in humans. Nutrition (Burbank, Los Angel County, Calif) 29:1127-1132. https:// doi.org/10.1016/j.nut.2013.03.003

Deminice R, Rosa FT, Franco GS, da Cunha SF, de Freitas EC, Jordao AA (2014) Short-term creatine supplementation does not reduce increased homocysteine concentration induced by acute exercise in humans. Eur J Nutr 53:1355-1361. https://doi.org/10.1007/ s00394-013-0636-1

Deminice R, Ribeiro DF, Frajacomo FTT (2016) The effects of acute exercise and exercise training on plasma homocysteine: a metaanalysis. PLoS One 11:e0151653

Dill DB, Costill DL (1974) Calculation of percentage changes in volumes of blood, plasma, and red cells in dehydration. J Appl Physiol 37:247-248

Evans GH, Shirreffs SM, Maughan RJ (2009) Postexercise rehydration in man: the effects of carbohydrate content and osmolality of drinks ingested ad libitum. Appl Physiol Nutr Metab Physiologie appliquee nutrition et metabolisme 34:785-793. https://doi. org/10.1139/H09-065
Frosst P et al (1995) A candidate genetic risk factor for vascular disease: a common mutation in methylenetetrahydrofolate reductase. Nat Genet 10(1):111-113

Fukuda N, Hamajima N, Wakai K, Suzuki K (2014) A cross-sectional study to find out the relationship of methylenetetrahydrofolate reductase (MTHFR) C677T genotype with plasma levels of folate and total homocysteine by daily folate intake in Japanese. J Nutr Sci Vitaminol 60:231-238

Gelecek N, Teoman N, Ozdirenc M, Pinar L, Akan P, Bediz C, Kozan $\mathrm{O}$ (2007) Influences of acute and chronic aerobic exercise on the plasma homocysteine level. Ann Nutr Metab 51:53-58

Gibala MJ (2001) Regulation of skeletal muscle amino acid metabolism during exercise. Int J Sport Nutr Exerc Metab 11:87-108

González VC, Perovic NR, Defagó MD (2016) Polimorfismo C677T de la enzima 5, 10-metilenetetrahidrofolato reductasa (MTHFR) y enfermedad cardiovascular. Diaeta 34:40-47

Gonzalez-Alonso J, Crandall CG, Johnson JM (2008) The cardiovascular challenge of exercising in the heat. J Physiol 586:45-53

González-Gross M, Sola R, Castillo MJ (2002) Folato: una vitamina en constante evolución. Medicina clínica 119:627-635

Guzel NA, Pinar L, Colakoglu F, Karacan S, Ozer C (2012) Long-term callisthenic exercise-related changes in blood lipids, homocysteine, nitric oxide levels and body composition in middle-aged healthy sedentary women. Chin J Physiol 55:202-209

Herrmann M, Schorr H, Obeid R, Scharhag J, Urhausen A, Kindermann W, Herrmann W (2003a) Homocysteine increases during endurance exercise. Clin Chem Lab Med CCLM/FESCC 41:1518-1524. https://doi.org/10.1515/CCLM.2003.233

Herrmann M, Schorr H, Obeid R, Scharhag J, Urhausen A, Kindermann W, Herrmann W (2003b) Homocysteine increases during endurance exercise. Clin Chem Lab Med 41:1518-1524

Herrmann M et al (2003c) Comparison of the influence of volumeoriented training and high-intensity interval training on serum homocysteine and its cofactors in young, healthy swimmers. Clin Chem Lab Med CCLM/FESCC 41:1525-1531. https://doi. org/10.1515/CCLM.2003.234

Iglesias-Gutierrez E et al (2012) Transient increase in homocysteine but not hyperhomocysteinemia during acute exercise at different intensities in sedentary individuals. PLoS One 7:e51185. https:// doi.org/10.1371/journal.pone.0051185

Jakovljevic B, Gasic B, Kovacevic P, Rajkovaca Z, Kovacevic T (2015) Homocystein as a risk factor for developing complications in chronic renal failure. Mater Socio Med 27:95

Joubert LM, Manore MM (2006) Exercise, nutrition, and homocysteine. Int J Sport Nutr Exerc Metab 16:341-361

Konig D, Bisse E, Deibert P, Muller HM, Wieland H, Berg A (2003) Influence of training volume and acute physical exercise on the homocysteine levels in endurance-trained men: interactions with plasma folate and vitamin B12. Ann Nutr Metab 47:114-118

Kumudini N, Uma A, Naushad SM, Mridula R, Borgohain R, Kutala VK (2014) Association of seven functional polymorphisms of one-carbon metabolic pathway with total plasma homocysteine levels and susceptibility to Parkinson's disease among South Indians. Neurosci Lett 568:1-5

Laitano O, Kalsi KK, Pearson J, Lotlikar M, Reischak-Oliveira A, Gonzalez-Alonso J (2012) Effects of graded exercise-induced dehydration and rehydration on circulatory markers of oxidative stress across the resting and exercising human leg. Eur J Appl Physiol 112:1937-1944. https://doi.org/10.1007/s00421-011-2170-2

Maroto-Sanchez B, Valtuena J, Albers U, Benito PJ, Gonzalez-Gross M (2013) Acute physical exercise increases homocysteine concentrations in young trained male subjects. Nutr Hosp 28:325-332. https ://doi.org/10.3305/nh.2013.28.2.6300

Maroto-Sanchez B, Lopez-Torres O, Palacios G, Gonzalez-Gross M (2016) What do we know about homocysteine and exercise? 
A review from the literature. Clin Chem Lab Med. https://doi. org/10.1515/cclm-2015-1040

Molina-López J, Molina JM, Chirosa LJ, Florea DI, Sáez L, Planells E (2013) Effect of folic acid supplementation on homocysteine concentration and association with training in handball players. J Int Soc Sports Nutr 10:10

Myers J, Bellin D (2000) Ramp exercise protocols for clinical and cardiopulmonary exercise testing. Sports Med 30:23-29

Okura T et al (2006) Effect of regular exercise on homocysteine concentrations: the HERITAGE Family Study. Eur J Appl Physiol 98:394-401

Petras M, Tatarkova Z, Kovalska M, Mokra D, Dobrota D, Lehotsky J, Drgova A (2014) Hyperhomocysteinemia as a risk factor for the neuronal system disorders. J Physiol Pharmacol 65:15-23

Powers SK, Howley ET (2007) Exercise physiology: theory and application to fitness and performance. McGraw-Hill, New York, NY

Randeva HS et al (2002) Exercise decreases plasma total homocysteine in overweight young women with polycystic ovary syndrome. J Clin Endocrinol Metab 87:4496-4501

Real JT, Merchante A, Gomez JL, Chaves FJ, Ascaso JF, Carmena R (2005) Effects of marathon running on plasma total homocysteine concentrations. Nutr Metab Cardiovasc Dis 15:134-139

Rennie MJ, Tipton KD (2000) Protein and amino acid metabolism during and after exercise and the effects of nutrition. Annu Rev Nutr 20:457-483

Sawka MN, Coyle EF (1999) Influence of body water and blood volume on thermoregulation and exercise performance in the heat. Exerc Sport Sci Rev 27:167-218

Sawka MN, Burke LM, Eichner ER, Maughan RJ, Montain SJ, Stachenfeld NS (2007) American College of Sports Medicine position stand exercise and fluid replacement. Med Sci Sports Exerc 39:377-390
Shen L, Ji H-F (2015) Associations between homocysteine, folic acid, vitamin B12 and Alzheimer's disease: Insights from meta-analyses. J Alzheimer's Dis 46:777-790

Shi Z et al (2015) Elevated total homocysteine levels in acute ischemic stroke are associated with long-term mortality. Stroke 46:2419-2425

Sotgia S, Carru C, Caria MA, Tadolini B, Deiana L, Zinellu A (2007) Acute variations in homocysteine levels are related to creatine changes induced by physical activity. Clin Nutr 26:444-449. https ://doi.org/10.1016/j.clnu.2007.05.003

Van Hall G, Saltin B, Wagenmakers AJ (1999a) Muscle protein degradation and amino acid metabolism during prolonged knee-extensor exercise in humans. Clin Sci (Lond, Engl 1979) 97:557-567

Van Hall G, Saltin B, Wagenmakers AJM (1999b) Muscle protein degradation and amino acid metabolism during prolonged kneeextensor exercise in humans. Clin Sci 97:557-567

Venta R, Cruz E, Valcarcel G, Terrados N (2009) Plasma vitamins, amino acids, and renal function in postexercise hyperhomocysteinemia. Med Sci Sports Exerc 41:1645-1651. https://doi. org/10.1249/MSS.0b013e31819e02f2

Vincent KR, Braith RW, Bottiglieri T, Vincent HK, Lowenthal DT (2003) Homocysteine and lipoprotein levels following resistance training in older adults. Prev Cardiol 6:197-203

Vincent HK, Bourguignon C, Vincent KR (2006) Resistance training lowers exercise-induced oxidative stress and homocysteine levels in overweight and obese older adults. Obesity 14:1921-1930

Zinellu A, Sotgia S, Zinellu E, Chessa R, Deiana L, Carru C (2006) Assay for the simultaneous determination of guanidinoacetic acid, creatinine and creatine in plasma and urine by capillary electrophoresis UV-detection. J Sep Sci 29:704-708 